\title{
Relationship of redundant Th17 cells and IL-17A, but not IL-17 F, with the severity of obstructive sleep apnoea/hypopnoea syndrome (OSAHS)
}

\author{
Lin Ying, Hequan Li , Zhijie Pan, Shanni Ma, Pei Zhang, Qing Wang, Guohua Lu and Jianying Zhou*
}

\begin{abstract}
Background: The pathogenesis of obstructive sleep apnoea/hypopnoea syndrome (OSAHS), a highly prevalent disease, is not completely understood. The purpose of this study was to investigate the contributions of Th17 cells and the Th17-associated cytokines IL-17A and IL-17 F to OSAHS.

Methods: 46 male patients with a clinical suspicion of OSAHS were enrolled and divided into four groups based on their polysomnography results: controls and mild, moderate, and severe OSAHS. The serum levels of IL-17A and IL-17 F were determined by enzyme linked immunosorbent assay (ELISA), pulmonary arterial pressure (PAP) was determined by echocardiography, and Th17 cell frequencies in peripheral blood were measured by flow cytometry.

Results: Serum IL-17A levels in the severe group were elevated (median value: control group $0.89 \mathrm{pg} / \mathrm{ml}$, mild OSAHS $1.02 \mathrm{pg} / \mathrm{ml}$, moderate OSAHS $1.18 \mathrm{pg} / \mathrm{ml}$, and severe OSAHS $1.62 \mathrm{pg} / \mathrm{ml} ; \mathrm{p}<0.05)$ and positively correlated with AHI $(r=0.52, p<0.05)$ but negatively related to the mean $\mathrm{O}_{2}$ saturation and lowest $\mathrm{O}_{2}$ saturation $(r=-0.349, p<0.05$; and $r=-0.336, p<0.05$, respectively). Although the frequencies of Th17 cells in the OSAHS groups were higher than that in the control group, these differences were not significant $(p=0.275)$. Pulmonary arterial hypertension was not present in our patients as the median PAP of the normal control and the mild, moderate, and severe OSAHS groups were 26, 27.5, 24.5, and $25.5 \mathrm{mmHg}$, respectively $(p=0.676)$.
\end{abstract}

Conclusion: IL-17A may be involved in the pathogenesis of OSAHS and may represent a target for therapeutic intervention.

Keywords: Obstructive sleep apnea hypopnea syndrome, Th17 cell, IL-17, Pulmonary arterial hypertension, Inflammation

\section{Background}

Obstructive sleep apnoea/hypopnoea syndrome (OSAHS) is a breathing disorder that occurs during sleep. The prevalence of OSAHS among adults is high, with estimates of $3-7 \%$ of men and $2-5 \%$ of women [1]. The main characteristics of OSAHS are repeated episodes of partial or complete obstruction of the upper airway, which causes markedly reduced (hypopnoea) or absent (apnoea) airflow, and intermittent hypoxia and sleep deprivation that result from these episodes of obstructed breathing. OSAHS has been shown to be an independent risk factor for cardiovascular and cerebrovascular diseases such as

\footnotetext{
*Correspondence: lihequan@zju.edu.cn; zjyhz@zju.edu.cn

Department of Respiratory Diseases, First Affiliated Hospital of Zhejiang, University School of Medicine, Zhejiang University, Zhejiang, P.R. China
}

systemic arterial hypertension, coronary artery disease, heart failure, and stroke [2,3]. The mechanisms involved in the associations between OSAHS and vascular diseases are also complex. Animal and clinical data suggest that intermittent hypoxia in OSAHS impairs endothelial function by altering the regulation of endothelial vasomotor tone and repair capacity while promoting vascular inflammation and oxidative stress [4].

Many immune system cell types, particularly $\mathrm{T}$ lymphocytes, participate in the pathogenesis of OSAHS. Dyugovskaya and colleagues reported that the $\mathrm{CD}^{+} \mathrm{T}$ lymphocytes from obstructive sleep apnoea patients undergo both phenotypic and functional changes, rendering them cytotoxic to target cells such as vascular endothelial cells [5]. Recently, Tan et al. examined the populations of Th1, 
Th2, and Treg cells in the peripheral blood of children with OSAHS and demonstrated that paediatric OSA is associated with a reduced Treg population and a Th1/Th2 balance that is shifted toward Th1 predominance [6].

Th17 cells, a recently discovered subset of T helper cells with a highly inflammatory nature, can secrete several potent proinflammatory cytokines, including IL-17A and IL-17 F, and are broadly implicated in inflammatory and autoimmune diseases [7-9]. However, the pathological effects of Th17 cells and their associated cytokines on OSAHS have not been determined. Kobi Sade and colleagues demonstrated that decreased ratios of Th17/Treg subpopulations may be involved in the pathogenesis of adenoid hypertrophy [10], which is the main cause of paediatric OSAHS [11]. In this study, we have explored the contributions of Th17 cells and their associated cytokines, IL-17A and IL-17 F, to OSAHS in adults.

\section{Methods}

\section{Patients}

Among the patients who visited our sleep disorders centre with a clinical suspicion of OSAHS, 46 male patients were enrolled in the study. All subjects underwent full-night polysomnography (Artisan, Rembrandt, USA), and 37 patients were diagnosed as having OSAHS, with an apnoea-hypopnoea index $(\mathrm{AHI})>5$ (mild:AHI $5 \sim 15$, $\mathrm{n}=10$; moderate: AHI $15 \sim 30, \mathrm{n}=11$; severe: $\mathrm{AHI}>30$, $\mathrm{n}=16$ ). The $\mathrm{AHI}$ is the average number of apnoea and hypopnoea episodes per hour of sleep. No patient had previously been diagnosed with or treated for OSAHS. All subjects were free of any acute or chronic infection, cardiovascular diseases, and cancer and were taking no medications. This study was approved by the Ethics Committee of the First Affiliated Hospital of the Zhejiang University School of Medicine, Zhejiang University. Written informed consent was obtained from all subjects.

\section{Polysomnography}

The presence and severity of OSAHS were determined by standard overnight polysomnography using electroencephalogram (EEG), electrooculogram (EOG), electrocardiogram (ECG), chin electromyogram, and measurements of oxygen saturation, airflow, and costal and abdominal movements when breathing. Apnoea was defined as a $\geq 90 \%$ decrease in airflow for at least $10 \mathrm{~s}$ relative to baseline. Hypopnoea was defined as a $\geq 50 \%$ decrease in airflow relative to baseline, with an associated $\geq 3 \%$ oxygen desaturation lasting at least $10 \mathrm{~s}$ [12]. As measured by AHI, there were three levels of OSAHS: mild $(5 \leq \mathrm{AHI}<15)$, moderate $(15 \leq \mathrm{AHI}<30)$, and severe $(\mathrm{AHI} \geq 30)$.

\section{Measurement of IL-17A and IL-17 F levels}

Blood samples were obtained from the antecubital vein on the morning after polysomnography and then centrifuged immediately at 3,000 rpm for $10 \mathrm{~min}$. Plasma samples were stored at $-80^{\circ} \mathrm{C}$ until use. The IL-17A and IL-17 F levels were determined quantitatively using a platinum enzyme-linked immunosorbent assay (eBioscience, San Diego, CA). The minimum detectable doses of IL-17A and IL-17 F were $0.23 \mathrm{pg} / \mathrm{ml}$ and $31.3 \mathrm{pg} / \mathrm{ml}$, respectively, and the intra-assay coefficient of variation was $<10 \%$.

\section{Flow cytometry}

Because we found a correlation between the serum level of IL-17 and OSAHS, we conducted follow-up visits with the study subjects to conduct additional research. However, only 17 subjects received a follow-up appointment and participated further in our research.

Intracellular cytokines were studied by flow cytometry. FITC-labelled anti-human CD4 (eBioscience) and PElabelled anti-human IL-17 (eBioscience) were used to detect the Th17 cells. PBMCs, obtained from heparinised peripheral whole blood $(400 \mu \mathrm{l})$, were added to $1 \mathrm{ml}$ of 1640 medium (PAA Laboratories, Pasching, Austria) and incubated for $6 \mathrm{~h}$ at $37^{\circ} \mathrm{C}$ with $5 \% \mathrm{CO}_{2}$ in the presence of $50 \mathrm{ng} / \mathrm{mL}$ phorbol myristate acetate (PMA) (BioVision, Mountain View, CA), $500 \mathrm{ng} / \mathrm{mL}$ ionomycin (Fermentek, Jerusalem, Israel), and $1 \mu \mathrm{l}$ of GolgiPlug (eBioscience). The cells were then stained with FITC-labelled anti-human CD4. After fixation and permeabilisation, the cells were stained with PE-labelled anti-human IL-17. Finally, the stained cells were analysed by flow cytometry using a FACS Calibur (BD Biosciences), and the results were analysed with CellQuest software (BD Biosciences).

\section{Measurement of pulmonary arterial pressure (PAP)}

Doppler echocardiography, using Vivid 7 (GE Vingmed Ultrasound, Horten, Norway) with a $2.5-\mathrm{MHz}$ transducer (Accuson Cypress, Siemens, Germany), was performed by an experienced sonographer blinded to the study. The peak velocity of the tricuspid regurgitation jet was used to assess the PAP.

\section{Statistical analysis}

Statistical analysis was performed using SPSS statistical software (SPSS, version 16.0 for Windows; SPSS Inc., Chicago, IL). The data were analysed using the KruskalWallis and Mann-Whitney tests. The Pearson test was used to assess the correlation between variables. Differences were considered significant at $\mathrm{p}<0.05$.

\section{Results}

\section{Demographic and sleep characteristics of subjects}

A total of 46 male patients were analysed, with 37 in the OSAHS group $(\mathrm{AHI} \geq 5)$ and 9 in the control group $(\mathrm{AHI}<5)$. The characteristics of the study population are shown in Table 1 . The median ages of the normal 
Table 1 Demographic and polysomnographic characteristics of the subjects $(n=46)$

\begin{tabular}{llllll}
\hline & Control group $(\mathbf{n}=\mathbf{9})$ & Mild OSAHS $(\mathbf{n}=\mathbf{1 0})$ & Moderate OSAHS $(\mathbf{n}=\mathbf{1 1})$ & Severe OSAHS $(\mathbf{n}=\mathbf{1 6})$ & $\mathbf{p}$ value \\
\hline Age $($ years $)$ & $50(22,63)$ & $47.5(39,61)$ & $42(30,65)$ & $43.5(25,70)$ & 0.823 \\
$\mathrm{BMI}\left(\mathrm{kg} / \mathrm{m}^{2}\right)$ & $24.6(22,30.8)$ & $26.9(22.6,30.8)$ & $26(22.5,31.6)$ & $29.4(23.7,38.4)^{*}$ & 0.029 \\
$\mathrm{AHI}($ events/h) & $1.2(0.1,3.6)$ & $8.6(5.7,15)^{*}$ & $26.2(15.1,30)^{* \#}$ & $50.7(40.7,91.4)^{*} \Delta$ & 0.000 \\
Lowest $\mathrm{SaO}_{2}(\%)$ & $91(86,95)$ & $81(67,88)^{*}$ & $80(69,87)^{*}$ & $63(32,79)^{*} \# \Delta$ & $<0.001$ \\
Mean $\mathrm{SaO}_{2}(\%)$ & $97(96,98)$ & $96(94,97)$ & $96(94,98)$ & $90.5(85,96)^{* \# \Delta}$ \\
\hline
\end{tabular}

The Kruskal-Wallis test was used to assess the differences among groups, and the Mann-Whitney test was used to test the significance of the differences between two groups.

The data were summarised as median (minimum,maximum). ${ }^{*} \mathrm{p}<0.05$ versus control group; $\# \mathrm{p}<0.05$ versus mild OSAHS group; $\triangle \mathrm{p}<0.05$ versus moderate OSAHS group.

control and the mild, moderate, and severe OSAHS groups were $50,47.5,42$, and 43.5 years, respectively $(\mathrm{p}=0.823)$. The median BMI was $26.9,26$, and $29.4 \mathrm{~kg} / \mathrm{m}^{2}$ in the three OSAHS groups, respectively, and $24.6 \mathrm{~kg} / \mathrm{m}^{2}$ in the control group $(\mathrm{p}=0.029)$. In the severe group, the median oxygen saturation $\left(\mathrm{MSaO}_{2}\right)$ and lowest arterial oxygen saturation $\left(\mathrm{LSaO}_{2}\right)$ were significantly decreased compared with the mild and moderate groups.

\section{Elevated level of serum IL-17A is observed in patients with OSAHS}

The concentrations of IL-17A and IL-17 F were determined by ELISA in our experiments. The median IL-17A level for normal controls was $0.8 \mathrm{pg} / \mathrm{ml}$, which was lower than that for the OSAHS group. Moreover, the patients with more severe OSAHS tended to have higher IL-17A levels; this difference was significant $(\mathrm{p}<0.001)$ (Figure 1A).

The serum level of IL-17 F in the OSAHS group was higher than that in the normal group $(\mathrm{p}<0.05)$. However, the differences among the OSAHS groups were not significant $(\mathrm{p}>0.05)$ (Figure $1 \mathrm{~B})$.

\section{The concentration of IL-17A is related to the severity} of OSAHS

We found that the serum level of IL-17A in the OSAHS groups was higher than that in the normal control group. Further regression analysis showed that the concentration of IL-17A was positively correlated with AHI $(\mathrm{r}=0.520, \mathrm{p}<0.01)$ (Figure 2) and negatively correlated with $\mathrm{LSaO}_{2}(\mathrm{r}=-0.336, \mathrm{p}<0.05)$ (Figure 3) and $\mathrm{MSaO}_{2}$ $(\mathrm{r}=-0.349, \mathrm{p}<0.05)$ (Figure 4).

The frequency of Th17 cells in peripheral blood has an elevated trend in the OSAHS group

Among 46 patients, 17 patients did not receive any treatment after diagnosis and were in the process of having follow-up appointments. Table 2 lists each parameter. The percentages of peripheral blood $\mathrm{CD}^{+} \mathrm{T}$ lymphocytes that were also positive for intracellular IL-17 (i.e., Th17/CD4 ${ }^{+} \mathrm{T}$ cells) were determined for these patients (Figure 5). The frequencies of Th17 cells in the OSAHS groups trended higher compared with that in the control group; however, the frequencies decreased with increasing OSAHS severity. Overall, these differences were not significant $(\mathrm{p}=0.275)$.

\section{PAH was not present in our patients}

A resting mean pulmonary artery pressure (PAPm) $>25$ $\mathrm{mmHg}$ is the cut-off value for the diagnosis of manifest pulmonary arterial hypertension (PAH), as set forth at the 4th World Symposium on Pulmonary Hypertension held at Dana Point in the United States in 2008 [13]. In

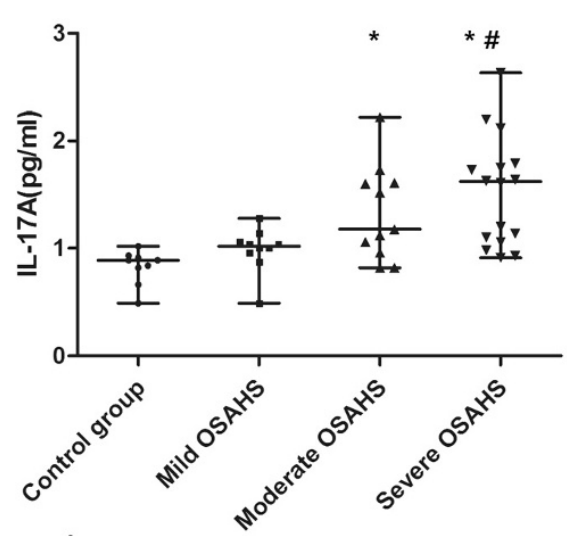

A

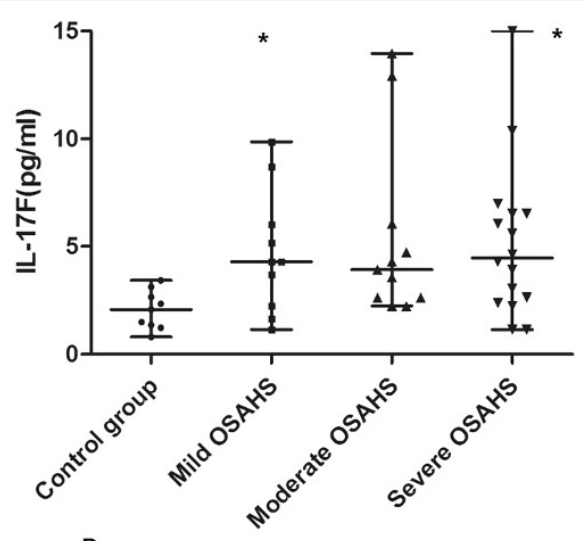

B

Figure 1 Serum level of IL-17A and IL-17 F were assessed by ELISA. The data are presented as median (minimum, maximum). ${ }^{*} p<0.05$ versus control group; \# $p<0.05$ versus mild OSAHS group. 


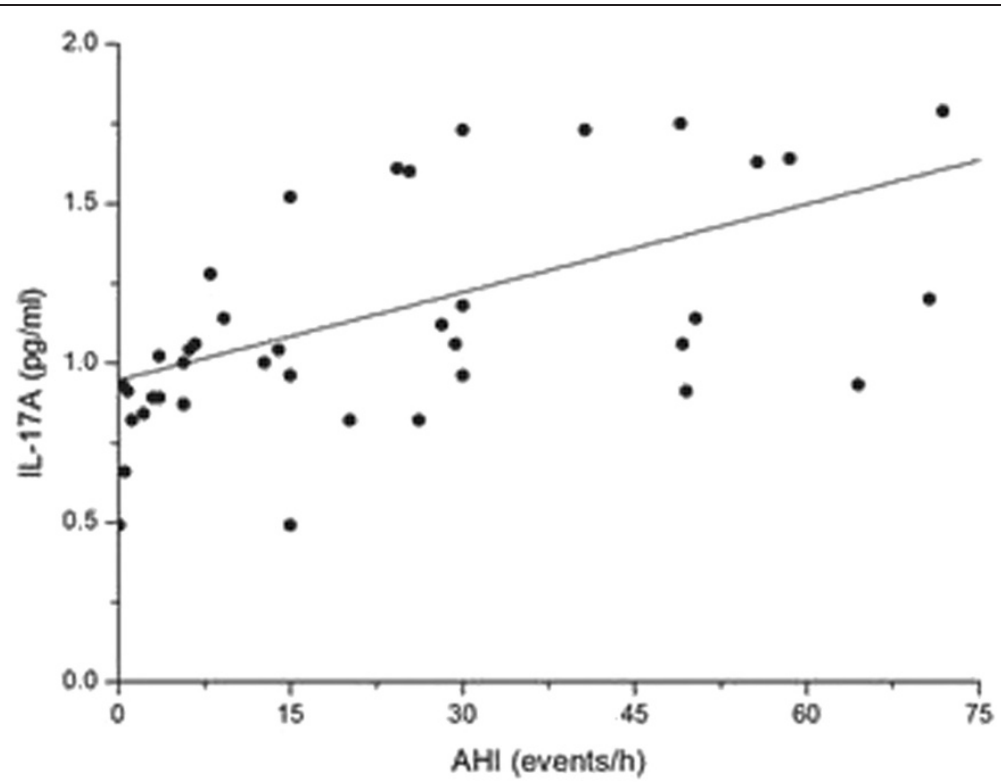

Figure 2 The relationship between AHI and IL-17A level. There was a significant positive relationship between AHI and the IL-17A level $(r=0.520, p<0.01)$.

our study, the PAP was calculated by echocardiography in 17 patients. Our data did not support a diagnosis of $\mathrm{PAH}$ in our patients as the median PAP of the normal control and the mild, moderate, and severe OSAHS groups was $26,27.5,24.5$, and $25.5 \mathrm{mmHg}$, respectively $(\mathrm{p}=0.676)($ Table 2$)$.

\section{Discussion}

Redundant Th17 cells and their associated cytokines have been shown to play a pathogenic role in autoimmune diseases and chronic inflammatory diseases, and these cells and cytokines may mediate many pathophysiological processes that occur with hypoxia. To investigate the

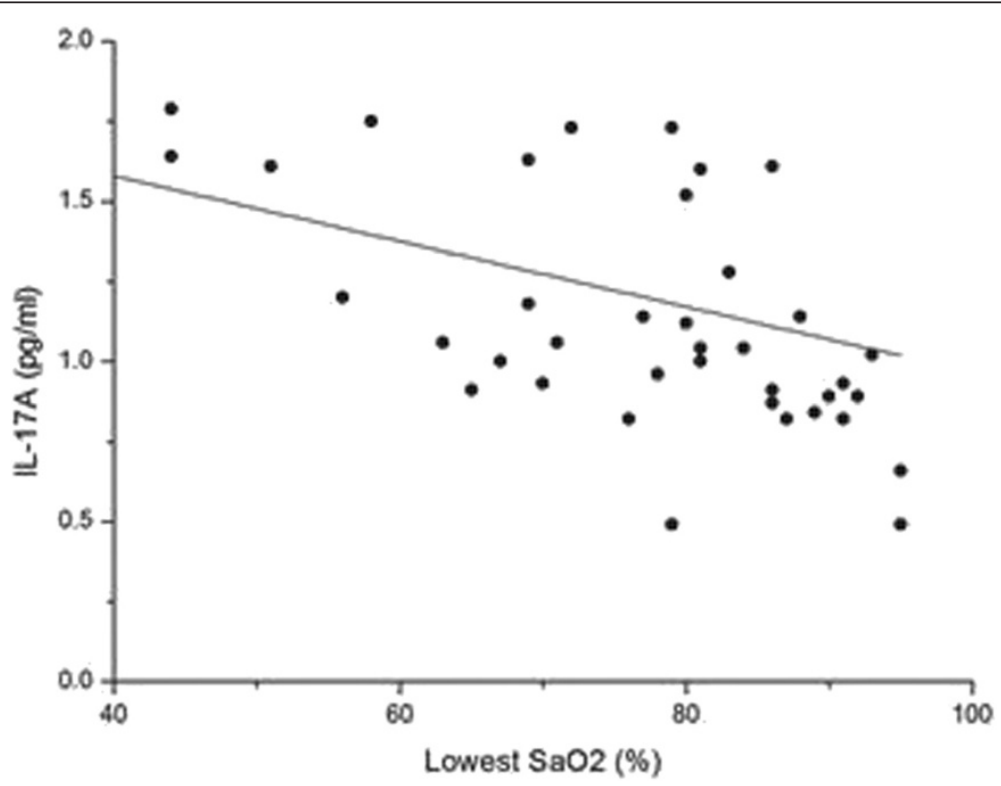

Figure 3 The relationship between $\mathrm{LSaO}_{2}$ and IL-17A level. There was a significant negative relationship between $\mathrm{LSaO}_{2}$ and the IL-17A level $(r=-0.336, p<0.05)$. 


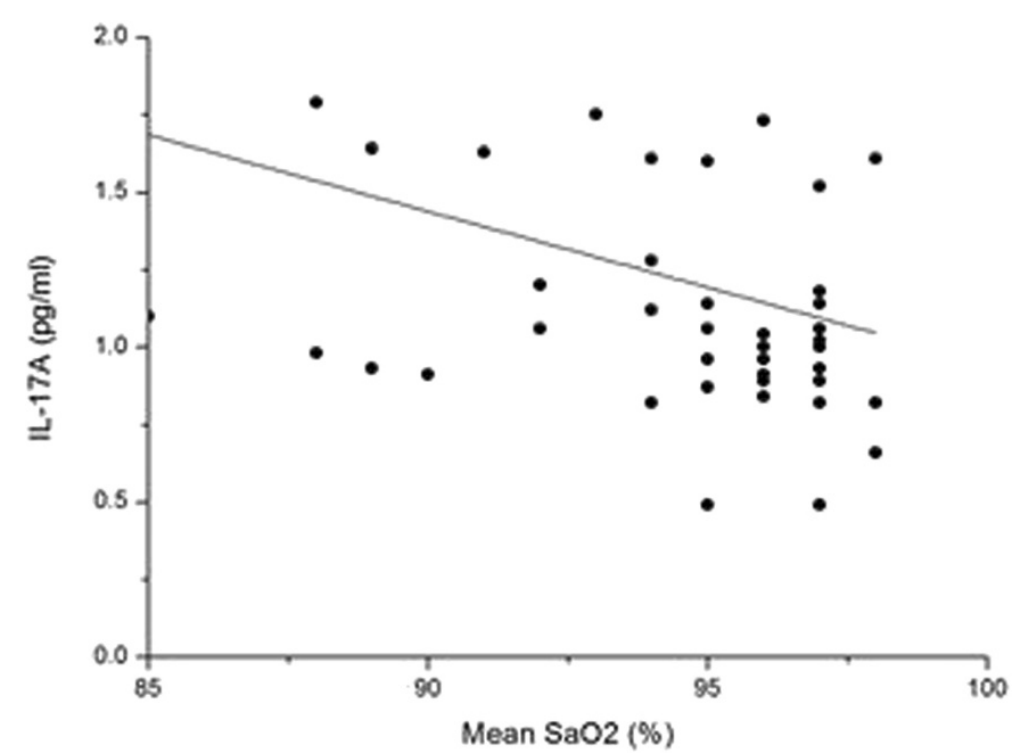

Figure 4 The relationship between $\mathrm{MSaO}_{2}$ and the IL-17A level. There was a significant negative relationship between $M \mathrm{MSO}_{2}$ and IL-17A level $(r=-0.349, p<0.05)$.

pathogenic role of Th17 cells and IL-17 in intermittent hypoxia, we measured the serum levels of IL-17A and IL17 F, PAP, and circulating Th17 cell frequencies in patients with OSAHS.

OSAHS is a common chronic sleep disorder, the pathogenesis of which is uncertain and likely to be a multifactorial process that includes sympathetic excitation, inflammation, and oxidative stress. Inflammation has been confirmed to play a crucial role due to the occurrence of recurrent hypoxia [14]. The unique form of hypoxia present in OSAHS, with repetitive short cycles of desaturation followed by rapid reoxygenation, termed intermittent hypoxia, similar to ischemia-reperfusion injury, is associated with a series of inflammatory responses through the induction of adhesion molecules and CRP in vascular endothelial cells and leukocytes $[15,16]$. Numerous studies have described an increase in the levels of systemic biomarkers of inflammation, including CRP and IL-6, in patients with OSAHS [17-19].

IL-6 is known to be an essential cytokine involved in inducing the differentiation of Th17 cells in both humans and mice. In the presence TGF- $\beta$, IL- 6 activates the expression of the critical Th17 transcription factor RORC (ROR $\gamma \mathrm{t}$ in mice) through the Jak/STAT3 pathway during Th17 cell development [20,21]. In view of this role of IL-6, we hypothesised that IL-17 levels may be elevated in patients with OSAHS, and our results confirm this hypothesis.

Our study made several novel observations. First, the serum levels of IL-17A, a proinflammatory cytokine, are increased in patients with OSAHS; second, these elevated levels of IL-17A are positively correlated with the severity of OSAHS. Although there were significant differences in the IL-17A concentrations, there was no significant difference in the Th17 ratios. The possible reasons for this lack

Table 2 Demographic and polysomnographic parameters, IL-17A concentrations, Th17 cell percentages, and PAP of the subjects $(n=17)$

\begin{tabular}{|c|c|c|c|c|c|}
\hline & Control group $(n=3)$ & Mild OSAHS $(n=4)$ & Moderate OSAHS $(n=4)$ & Severe OSAHS $(n=6)$ & $p$ value \\
\hline Age (years) & $50(37,61)$ & $46(39,59)$ & $47.5(35,65)$ & $50.5(42,59)$ & 0.979 \\
\hline BMI $\left(\mathrm{kg} / \mathrm{m}^{2}\right)$ & $26.1(23.8,30.8)$ & $26.1(24.8,30.4)$ & $25.5(22.5,31.1)$ & $27.3(23.7,35)$ & 0.787 \\
\hline Lowest $\mathrm{SaO}_{2}(\%)$ & $89(86,90)$ & $75(67,84)$ & $83(72,87)$ & $65(44,79)$ & 0.013 \\
\hline Mean $\mathrm{SaO}_{2}(\%)$ & $96(96,96)$ & $96.5(95,97)$ & $96.5(94,98)$ & $92(88,96)$ & 0.055 \\
\hline $\mathrm{AHI}$ (events/h) & $2.2(0.8,3.6)$ & $6.5(5.7,15)$ & $26.3(23.4,30)$ & $60.8(40.7,91.4)$ & 0.002 \\
\hline IL-17A (pg/ml) & $0.07(0.02,0.14)$ & $0.09(0.03,0.11)$ & $0.1(0.01,0.31)$ & $0.37(0.08,1.36)$ & 0.065 \\
\hline Th17\% & $2.2(0.6,6.0)$ & $8.5(4.3,9.5)$ & $6.6(2.7,13.4)$ & $6.6(4,10.6)$ & 0.275 \\
\hline PAP $(m m H g)$ & $26(23,26)$ & $27.5(23,30)$ & $24.5(23,26)$ & $25.5(22,30.6)$ & 0.676 \\
\hline
\end{tabular}



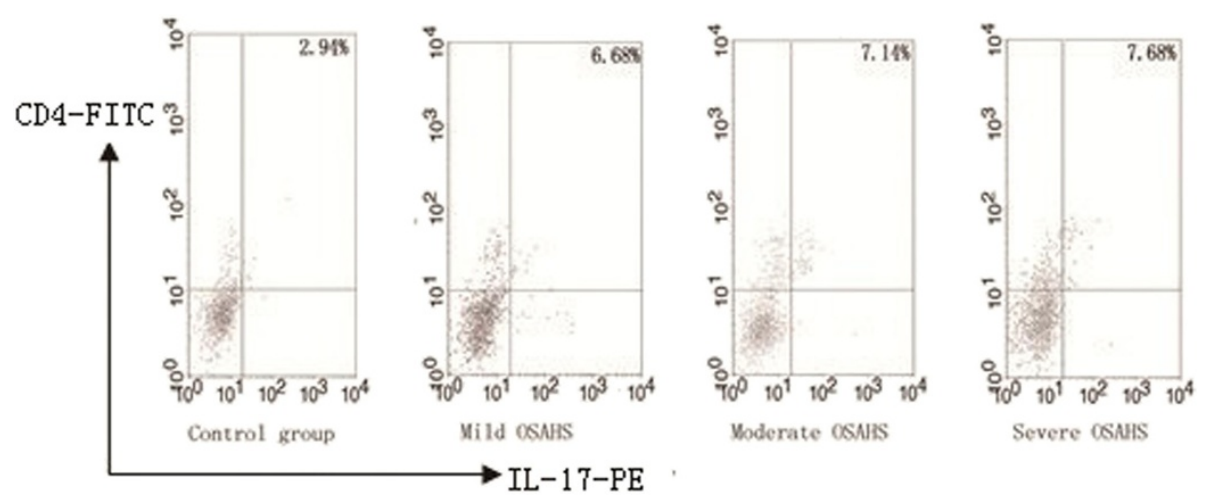

Figure 5 The percentage of $\mathrm{CD} 4^{+} \mathrm{IL}-17^{+}$cells. Single-cell suspensions prepared from the peripheral blood of 17 patients were double-stained with FITC-conjugated anti-CD4 and PE-conjugated anti-IL-17 and were analysed by flow cytometry.

of a difference in the Th17 frequency include limited sample size and the migration of Th17 cells. The first part of our study involved 46 study subjects, and for the second part of our study, we initially followed up with all of our study subjects. However, some of our subjects had already begun to receive treatment after their diagnosis, and such treatment would have confounded our results. Thus, for the second part of our study, we did not pursue patients who had already begun treatment. We also lost additional subjects to follow-up as a result of their unwillingness to participate further in our study. Moreover, the complexity and sensitive nature of flow cytometry makes the already small ratio of Th17 cells difficult to measure accurately.

We have shown that adults with OSAHS are more likely to exhibit an increase in circulating Th17 cells along with elevated IL-17A levels. Th17 cells are able to promote the activation, proliferation, and effector functions of a wide range of immune system cells, in contrast to Treg cells. Anderson and Tan recently described significant negative correlations between the severity of paediatric OSA and the percentage of Treg cells. An increase in the frequency of Th17 cells, together with a reduction in the frequency of Treg cells, could be a possible explanation for the link between OSAHS and inflammation [6,22].

Some authors have reported that daytime PAH was observed in severe OSAHS patients in the absence of significant heart or lung disease [23,24]. Moreover, OSAHS is frequently regarded as an independent risk factor for the development of pulmonary hypertension, and the European Respiratory Society (ERS) categorises OSAHS as a risk factor for PAH [25]. The ERS hypothesises that one crucial factor that may cause PAH in OSAHS is pulmonary vasoconstriction, which is a direct response to alveolar hypoxia and a cascade of biochemical and molecular events that culminate in pulmonary vascular remodelling $[26,27]$. However, PAH was not observed in our study, and we did not find any link between the severity of OSAHS and the level of PAP. The main reasons for this difference between the results of those studies and our results may be the limited number of patients studied, the length of illness, inter-individual differences in the response to factors such as hypoxia and different measurement methods for PAP.

There were also several limitations to our measurements of patients' PAP. First, we used transthoracic echocardiographic indices to calculate PAP. Right heart catheterisation is the gold standard for the diagnosis of PAH [25]. However, the establishment of a definite diagnosis with this invasive method is always hampered by several factors, including the risk to patients and patient unwillingness to undergo to this procedure. Second, as a result of loss to follow-up, only 17 patients had their PAP measured.

\section{Conclusions}

Our data offered direct evidence that IL-17A is elevated in patients with OSAHS and that the magnitude of this increase is associated significantly with the severity of OSAHS. As a pro-inflammatory cytokine, IL-17A may be an important factor linking OSAHS to systemic inflammation. However, the clinical utility of the IL-17A assay for the diagnosis of OSAHS and for the accurate evaluation of severity still needs to be studied further. In addition, large-scale, prospective studies are necessary to obtain better knowledge of the relationship among Th17 cells, PAP, and OSAHS.

\section{Abbreviations}

AHI: Apnoea hypopnoea index; BMI: Body mass index; CRP: C-reactive protein; ELISA: Enzyme-linked immunosorbent assay; FITC: Fluorescein isothiocyanate; JAK: Janus kinase; LSaO2: Lowest arterial oxygen saturation; MSaO2: Mean arterial oxygen saturation; OSAHS: Obstructive sleep apnoea/ hypopnoea syndrome; PAH: Pulmonary arterial hypertension; PAP: Pulmonary arterial pressure; PBMC: Peripheral blood mononuclear cell; PE: Phycoerythrin; ROR: Retinoid-related orphan receptor; ROS: Reactive oxygen species;

STAT: Signal transducers and activators of transcription.

\section{Competing interests}

The authors have no competing financial interests. 


\section{Authors' contributions}

LY: Performed experiments, analyzed data, wrote manuscript; HQL: performed analyses and assisted in procuring human blood sample, reviewed manuscript; ZJP: carried out full-night polysomnography, collected data; SNM and PZ: aided in data collection and analyses;QW and GHL: performed ELISA and flow cytometry, produced graphs and tables; JYZ: designed the study and assisted in generating the final manuscript. All authors have read and approved the final manuscript.

\section{Authors' information}

Department of Respiratory Diseases,First Affiliated Hospital of Zhejiang University School of Medicine,79 Qingchun Road, Hangzhou, Zhejiang 310003, P.R. China

\section{Acknowledgments}

This work was supported by Grants 81100020,81170038 , and 81170015 from the National Natural Science Foundation of China, Grant Y2100346 from the Natural Science Foundation of Zhejiang Province, China and by Grant Y201016825 and Y201328531 from the Department of education of Zhejiang Province, China.

Received: 18 October 2013 Accepted: 8 May 2014

Published: 15 May 2014

\section{References}

1. Lurie A: Obstructive sleep apnea in adults: epidemiology, clinical presentation, and treatment options. Adv Cardiol 2011, 146:1-42.

2. Peker $Y$, Hedner J, Kraiczi H, Löth S: Respiratory disturbance index: an independent predictor of mortality in coronary artery disease. Am J Respir Crit Care Med 2000, 162:81-86.

3. Kokturk O, Ciftci TU, Mollarecep E, Ciftci B: Elevated Creactive protein levels and increased cardiovascular risk in patients with obstructive sleep apnea syndrome. Int Heart J 2005, 46:801-809.

4. Zamarrón C1, Valdés Cuadrado L, Alvarez-Sala R: Pathophysiologic mechanisms of cardiovascular disease in obstructive sleep apnea syndrome. Pulm Med 2013, 521087.

5. Dyugovskaya L, Lavie P, Hirsh M, Lavie L: Activated CD8 ${ }^{+}$T-lymphocytes in obstructive sleep apnoea. Eur Respir J 2005, 25:820-828.

6. Tan HL, Gozal D, Wang Y, Bandla HP, Bhattacharjee R, Kulkarni R, KheirandishGozal L: Alterations in circulating T-cell lymphocyte populations in children with obstructive sleep apnea. Sleep 2013, 36:913-922.

7. Bettelli $E$, Oukka M, Kuchroo VK: $T(\mathrm{H})-17$ cells in the circle of immunity and autoimmunity. Nat Immunol 2007, I8:345-350.

8. Miossec P, Korn T, Kuchroo VK: Interleukin-17 and type 17 helper T cells N Engl J Med 2009, 361:888-898.

9. Maddur MS, Miossec P, Kaveri SV, Bayry J: Th17 cells: biology, pathogenesis of autoimmune and inflammatory diseases, and therapeutic strategies. Am J Pathol 2012, 181:8-18.

10. Sade K, Fishman G, Shmuel K, Ari DR, Sheila L: Expression of Th17 and Treg lymphocyte Subsets in hypertrophied adenoids of children and its clinical significance. Immunol Invest 2011, 40:657-666.

11. Katz ES, D'Ambrosio CM: Pathophysiology of pediatric obstructive sleep apnea. Proc Am Thorac Soc 2008, 5:253-262.

12. Epstein LJ, Kristo D, Strollo PJ Jr, Friedman N, Malhotra A, Patil SP, Ramar K, Rogers R, Schwab RJ, Weaver EM, Weinstein MD: Clinical guideline for the evaluation, management and long-term care of obstructive sleep apnea in adults. J Clin Sleep Med 2009, 5:263-276.

13. Nakanishi N1, European Society of Cardiology,European Respiratory Society: 2009 ESC/ERS pulmonary hypertension guidelines and connective tissue disease. Allergol Int 2011, 60:419-424.

14. Umur $H$, Israel $R$ : Inflammation and obstructive sleep apnea syndrome pathogenesis: a working hypothesis. Respiration 2003, 70:665-671.

15. El-Solh AA, Mador MJ, Sikka P, Dhillon RS, Amsterdam D, Grant BJ: Adhesion molecules in patients with coronary artery disease and moderate-tosevere obstructive sleep apnea. Chest 2002, 121:1541-1547.

16. Alam I, Lewis K, Stephens JW, Baxter JN: Obesity, metabolic syndrome and sleep apnoea: all pro-inflammatory states. Obes Rev 2007, 8:119-127.

17. Punjabi NM, Beamer BA: C-reactive protein is associated with sleep disordered breathing independent of adiposity. Sleep 2007, 30:29-34.

18. Umur $H$, Israel R: Inflammation and obstructive sleep apnea syndrome: how many ways do I look at them? Chest 2004, 126:1-2.
19. Teramoto $S$, Yamamoto $H$, Ouchi $Y$ : Increased plasma interleukin- 6 is associated with the pathogenesis of obstructive sleep apnea syndrome. Chest 2004, 125:1964-1965

20. Stockinger B, Veldhoen M: Differentiation and function of Th17 T cells. Curr Opin Immunol 2007, 19:281-286.

21. Zhu J, Paul WE: Heterogeneity and plasticity of T helper cells. Cell Res 2010, 20:4-12

22. Anderson ME Jr1, Buchwald ZS, Ko J, Aurora R, Sanford T: Patients with pediatric obstructive sleep apnea show altered T-Cell populations with a dominant TH17 profile. Otolaryngol Head Neck Surg 2014, Jan 31. [Epub ahead of print].

23. Arias MA, García-Río F, Alonso-Fernández A, Martínez I, Villamor J: Pulmonary hypertension in obstructive sleep apnoea: effects of continuous positive airway pressure: A randomized, controlled cross-over study. Eur Heart J 2006, 27:1106-1113.

24. Alchanatis M, Tourkohoriti G, Kakouros S, Kosmas E, Podaras S, Jordanoglou JB: Daytime pulmonary hypertension in patients with obstructive sleep apnea: the effect of continuous positive airway pressure on pulmonary hemodynamics. Respiration 2001, 68:566-572.

25. Galiè N, Hoeper MM, Humbert M, Torbicki A, Vachiery JL, Barbera JA, Beghetti M, Corris P, Gaine S, Gibbs JS, Gomez-Sanchez MA, Jondeau G, Klepetko W, Opitz C, Peacock A, Rubin L, Zellweger M, Simonneau G: Guidelines for the diagnosis and treatment of pulmonary hypertension. Eur Respir J 2009, 34:1219-1263.

26. Stenmark KR, Fagan KA, Frid MG: Hypoxia-induced pulmonary vascular remodeling: cellular and molecular mechanisms. Circ Res 2006, 99:675-691.

27. Adegunsoye A, Ramachandran S: Etiopathogenetic mechanisms of pulmonary hypertension in sleep-related breathing disorders. Pulm Med 2012, 273591.

\section{doi:10.1186/1471-2466-14-84}

Cite this article as: Ying et al:: Relationship of redundant Th17 cells and IL-17A, but not IL-17 F, with the severity of obstructive sleep apnoea/ hypopnoea syndrome (OSAHS). BMC Pulmonary Medicine 2014 14:84.

\section{Submit your next manuscript to BioMed Central and take full advantage of:}

- Convenient online submission

- Thorough peer review

- No space constraints or color figure charges

- Immediate publication on acceptance

- Inclusion in PubMed, CAS, Scopus and Google Scholar

- Research which is freely available for redistribution

Submit your manuscript at www.biomedcentral.com/submit
C Biomed Central 